\title{
Coordinated Low Voltage Ride through strategies for Permanent Magnet Direct Drive Synchronous Generators
}

\author{
Zhang Ge ${ }^{a}$, Yang Yiyun, Xiao Jing, Gao Like and Xiao Yuanyuan \\ Guangxi Power Grid Company Electric Power Research Institute, Nanning, 530000
}

\begin{abstract}
By analyzing the mechanism of the low voltage ride through on the permanent magnet direct drive synchronous wind power generating units, this paper proposes a coordinated control strategy for permanent magnet synchronous generator. In order to avoid over speed operation of the generation units, over voltage on DC capacitor and over current on convert, the improved pitch angle control and inverter control are used. When the grid voltage drops, the captured wind power is cut down by the variable pitch system, which limits the speed of the generator, the generator side converter keeps the DC capacitor voltage stabile; and the grid side converter provides reactive power to the grid to help the grid voltage recover. The control strategy does not require any additional hardware equipment, with existing control means, the unit will be able to realize low voltage ride through. Finally, based on Matlab/Simulink to build permanent magnet direct drive wind power generation system, the simulation results verify the correctness and effectiveness of the control strategy.
\end{abstract}

\section{Introduction}

As an important new energy power generation, wind power generation rapidly develop in China. In 2014, the whole country (except Taiwan) new capacity is $23196 \mathrm{MW}$ as an increase of $44.2 \%$ [1]. As the proportion of wind power in the power grid upgrade, due to grid failure or grid disturbances caused by voltage drop cause the wind turbines taking off network. Therefore, the study of wind turbines LVRT capability has important practical significance wanted [2].

Compared with double-fed unit, direct drive Permanent Magnet Synchronous Generator (PMSG) do not need rose -speed gearbox so has a small mechanical loss; no slip rings and brushes, to improve the operational reliability of the system [3], [4]. After a lot of PMSG connected to the grid, if you do not LVRT capability, when the grid fails, the unit will be a large area off the network, causing a tremendous impact on the stability of the grid [5], [6]. At present, domestic and foreign research workers have done a lot of research on the low voltage ride through of PMSG. Literature [7]-[9] by adding unloading resistance or energy storage element to ensure the unit PMSG in low voltage ride through, but additional hardware increases system cost and maintenance difficulty [10], [11]. Literature [12], [13] by limiting the grid failure PMSG power to limit electromagnetic converter from the input side to the DC side capacitance and grid-side power converter, the program improved the traditional converter control strategy to avoid an increase in redundant hardware protection device, but it does not restrict the ability of fans during a grid failure to capture wind energy, and therefore can't effectively reduce the burden LVRT unit.

In this paper, the performance characteristics of PMSG are analyzed in detail from the viewpoint of energy balance. Based on the theoretical analysis, combined with the existing low voltage ride through method, a new permanent magnet direct drive wind turbine low- voltage ride through coordinated control strategy has been put forward. The strategy take avoiding generator over speed and DC side capacitor voltage for the purpose, using the improvement of the pitch angle control and inverter control. Using the pitch control system, reduce the fan captured during grid fault wind energy, in order to avoid generator over speed; Monitoring DC bus voltage, once the capacitor voltage reaches the threshold, the controller responds quickly and avoids DC capacitor; according to the degree of grid voltage drop, providing dynamic reactive power to grid converter side through the network, to help restore the grid voltage.

\section{Operation characteristic analysis of power network fault}

Figure 1 is permanent magnet direct drive wind turbine system which consists of wind turbine, permanent magnet generator, generator side converter, DC capacitor, grid side converter, transformer and control system, etc.

The wind turbine is used to capture wind energy, which determines the power output of the whole wind

\footnotetext{
${ }^{\text {a }}$ Corresponding author.
} 
power system. The power of the wind turbine $P_{w}$ can be expressed as:

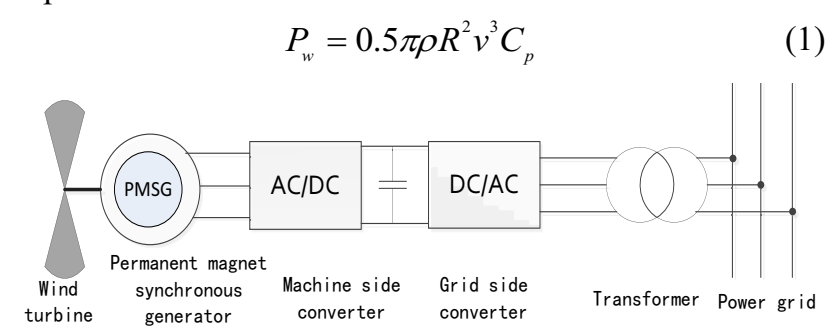

Figure 1. Structure diagram of wind turbines.

In the formula, $\rho$ is air density, unit is $\mathrm{kg} / \mathrm{m} 3 ; R$ is radius of wind wheel, unit is $\mathrm{m} ; \quad v$ is wind speed, unit is $\mathrm{m} / \mathrm{s} ; \quad C_{p}$ is wind energy utilization coefficient [14].

Analysis of transient characteristics of permanent magnet direct drive wind power system when the grid voltage drops from the viewpoint of energy conservation, Figure 2 is Internal power transfer diagram of wind turbines. $i_{s}, i_{g}, i_{d c}$ is the input current of the machine side, the network side and the DC capacitor; $U_{d c}$ is capacitor terminal voltage; $P_{s}, P_{g}$ is the input power of the machine side and the grid side converter.

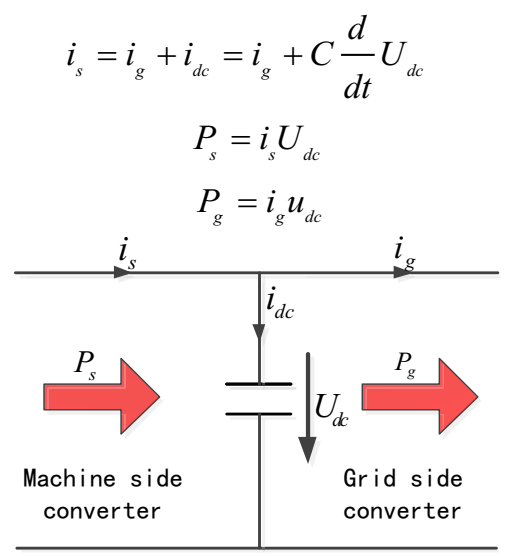

Figure 2. Internal power transfer diagram of wind turbines.

Under normal circumstances, the wind energy and the power of the wind turbine are equal to the electric energy of the transmission, that is $i_{s}$ equals $i_{g}$. At this point, the capacitor charge and discharge current $i_{d c}$ is 0 , rate of change of capacitance is 0 , capacitor terminal voltage is a fixed value at this time.

When power grid faults occur, the power of the converter to the power grid transmission power is greatly reduced, but due to the independence of the machine side converter, the input power of the machine side converter will remain relatively fixed, so that the excess input energy of the machine side converter will remain in the unit and the DC capacitor charging, leading to a surge in the capacitance of the capacitor, the mathematical formula is shown as follows:

$$
U_{d c}(t)=\sqrt{U_{d c}^{2}\left(t_{0}\right)+\frac{2}{C} \int_{t_{0}}^{t}\left(P_{s}(\tau)-P_{g}(\tau)\right) d_{\tau}}
$$

In the formula, $t_{0}$ is time of low voltage occur; $t_{r}$ is time of grid voltage recovery.

Therefore, it is necessary to use the appropriate control strategy to reduce the power grid fault in the unbalanced energy, in order to improve the low voltage ride through PMSG.

\section{Coordinated control strategy}

\subsection{Pitch control strategy}

The pitch angle control system determines the ability of fan wind energy capture. Wind speed at rated value and pitch angle control system does not work, pitch angle is 0 .When the wind speed is higher than the rated value, control system by increasing the pitch angle to reduce wind energy capture, in order to avoid generator overspeed. Figure 3 shows the pitch angle control system structure diagram [15].

Under normal circumstances, the rotor speed $\omega_{m}$ is the input signal of pitch angle control system, when the rotor speed $\omega_{m}$ exceeds the given maximum speed value, the pitch angle control system works in order to reduce the wind turbine output. When power grid fault happens, pitch angle reference value replaces by given grid tolerable lower limits value $U_{\text {gref }}$, when the power grid voltage drop is detected, the pitch angle control system work immediately and pitch angle increases rapidly. The servo link can simulate the dynamic response process of pitch system, limits changing speed and changing range of the pitch angle.

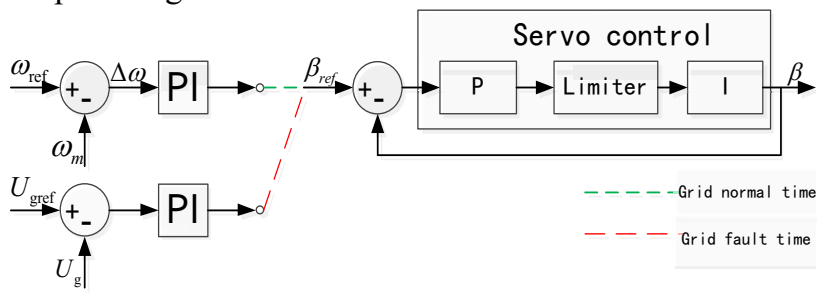

Figure 3. Pitch control system structure diagram.

\subsection{Generator-Side converter control strategy}

The motor side converter can control the speed of the generator running at optimal tip speed ratio, so as to achieve the purpose of maximum wind energy capture. Stator voltage equation and torque equation of permanent magnet synchronous motor [16]:

$$
\left\{\begin{array}{l}
u_{s d}=R_{s} i_{s d}+L_{d} \frac{d}{d t} i_{s d}-\omega_{s} L_{q} i_{s q} \\
u_{s q}=R_{s} i_{s q}+L_{q} \frac{d}{d t} i_{s q}+\omega_{s} L_{d} i_{s d}+\omega_{s} \psi_{f} \\
T_{e}=1.5 n_{p} i_{s q}\left[\left(L_{q}-L_{d}\right) i_{s d}+\psi_{f}\right]
\end{array}\right.
$$

In the formula: $u_{s d}, u_{s q}$ and $i_{s d}, i_{s q}$ are respectively indicate $\mathrm{d}$ and $\mathrm{q}$ axis components of stator 
voltage and stator current, $R_{s}$ indicates the stator resistance, $L_{d}, L_{q}$ are respectively indicate $\mathrm{d}$ and $\mathrm{q}$ axis components of stator inductance. $\omega_{s}$ is the generator power angular velocity; $n_{p}$ is the generator pole number; $\psi_{f}$ is the permanent magnet flux.

For the non-salient pole permanent magnet direct drive generator, the excitation flux and the pole number are constant, $\mathrm{L}_{\mathrm{d}}$ equals $\mathrm{L}_{\mathrm{q}}$, and the electromagnetic torque equation of the generator can be rewritten:

$$
T_{e}=1.5 n_{p} i_{s q} \psi_{f}
$$

The generator side converter adopts double closed loop control based on stator flux orientation, the reference value of generator $\mathrm{d}$-axis current $i_{\text {sdref }}$ is zero, q-axis current controls the output active power of generator, and the control structure of generator side converter is shown in Figure 4.

Under normal condition, the speed reference value of the generator rotor $\omega_{\text {ref }}$ is obtained by the maximum wind power tracking algorithm. The active power current reference value $i_{\text {sdref }}$ is controlled by the error between $\omega_{r e f}$ and $\omega_{m}$ through PI controller. During the grid fault, the DC capacitor voltage is controlled by the generator side converter control. When the DC voltage $U_{d c}$ is higher than the rated value $U_{d c r e f}$, the controller works to avoid DC capacitor over voltage.

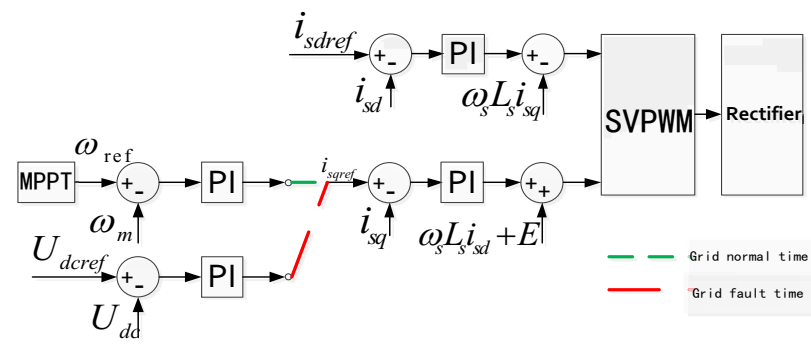

Figure 4. Control structure diagram of generator side converter.

\subsection{Control strategy of grid side converter}

On the one hand, the grid side converter makes the DC capacitor voltage remain stable and the active power injected into the power grid. On the other hand, according to the needs of the power grid, outputs a certain reactive power.

In the synchronous rotating $\mathrm{d}-\mathrm{q}$ coordinate system, the voltage equation of the grid side converter is:

$$
\left\{\begin{array}{l}
u_{d}=u_{g d}-R i_{d}-L \frac{d}{d t} i_{d}+\omega L i_{q} \\
u_{q}=u_{g q}-R i_{q}-L \frac{d}{d t} i_{q}-\omega L i_{d}
\end{array}\right.
$$

In the formula: $u_{g d}, u_{g q}$ are respectively indicate $\mathrm{d}$ and $\mathrm{q}$ axis components of grid voltage, $i_{d}, i_{q}$ are respectively indicate $\mathrm{d}$ and $\mathrm{q}$ axis components of grid current. $\mathrm{R}$ and $\mathrm{L}$ are the resistance and inductance of the reactor.

Grid side converter using vector control based on voltage oriented. The $\mathrm{d}$-axis in the synchronous rotating $\mathrm{d}-\mathrm{q}$ coordinate system is selected as grid side voltage space vector direction, and the q-axis is 90 degrees advanced q-axis, then the decoupling control of active power and reactive power is realized. The active power of the power grid is only related to the d-axis current, the reactive power is related to the $\mathrm{q}$-axis current, active power $\mathrm{P}$ and reactive power $\mathrm{Q}$ of the grid side converter are as follows:

$$
\left\{\begin{array}{l}
P_{g}=1.5 u_{g d} i_{d} \\
Q=1.5 u_{g q} i_{q}
\end{array}\right.
$$

The control structure of the grid side converter is shown in Figure 5. Under normal circumstances, the grid side converter uses the voltage outer loop and current inner loop control structure. The voltage outer loop can maintain the stability of the DC capacitor voltage and the inner loop can realize the stable operation and fast dynamic response of the control system. When the grid fault happens, the network side converter will output a certain reactive power to help the recovery of the grid voltage based on the voltage sag degree of the power grid. First, according to the need of compensate reactive power to calculate reactive current reference value $i_{\text {gqref }}$, and then calculate the active current reference value $i_{\text {gdref }}$ in accordance with the requirements of the current limiter.

$$
i_{\text {gdref }}=\sqrt{I_{N}^{2}-I_{\text {gqref }}^{2}}
$$

In the formula: $I_{N}$ is the rated current of the power grid.

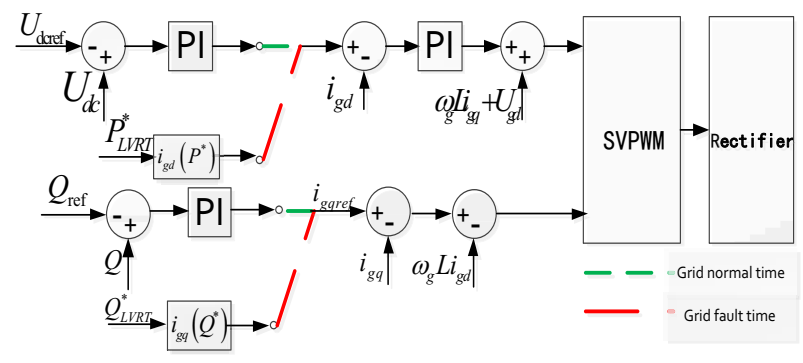

Figure 5. Control structure diagram of grid side converter.

\section{Simulation study}

\subsection{Data preparation}

To test correctness and validity of the proposed low voltage ride through control strategy on permanent magnet direct drive wind turbine, this paper respectively emulate two examples of different grid voltage dropping degree based on MATLAB/Simulink. Before the grid fault occurs, the permanent magnet direct drive wind turbine operates under the rated wind speed, and the system is running in the unit power factor condition. The simulation parameters are shown in Table 1. 
Table 1. System simulation parameters.

\begin{tabular}{|c|c|}
\hline Device name & Technical parameters \\
\hline Wind turbine & $\begin{array}{c}\text { Air density } 1.225 \mathrm{~kg} / \mathrm{m} 3 \text {, Blade radius } \\
38.8 \mathrm{~m}\end{array}$ \\
\hline $\begin{array}{l}\text { permanent } \\
\text { magnet direct } \\
\text { drive }\end{array}$ & $\begin{array}{c}\text { Rated power } 1 \mathrm{MW} \text {, rated voltage } 690 \mathrm{~V}, \\
\text { pole number } 40\end{array}$ \\
\hline $\begin{array}{l}\text { Grid side } \\
\text { converter }\end{array}$ & $\begin{array}{c}\text { Reactor resistance } 0.002 \text {, inductance } \\
0.3 \mathrm{mH} \text {, grid voltage } 690 \mathrm{~V} \\
\end{array}$ \\
\hline Capacitor & $\begin{array}{c}\text { DC capacitor } 100 \mathrm{mF} \text {, set up voltage } \\
1500 \mathrm{~V}\end{array}$ \\
\hline
\end{tabular}

\subsection{Case analysis}

Case 1: The light drop of grid voltage simulation

At $0.4 \mathrm{~s}$, the grid voltage occurs the three-phase symmetrical drop fault, the drop depth is $30 \%$, the duration time is $200 \mathrm{~ms}$, and at $0.6 \mathrm{~s}$ grid voltage recovers, as is shown in Figure 6(a). After the grid fault occurs, pitch angle control system begins to work, the pitch angle increases to decrease the wind energy captured by wind turbine, and the rotating speed of the generator increases as is shown in Figure 6(b) and Figure 6(c). By Figure 6(d), the capacity of the grid side converter to transfer power to the grid is reduced to $0.4 \mathrm{MW}$. The DC capacitor terminal voltage will have a transient overshoot, but under the machine side converter control system, the terminal voltage slowly drops until the normal value, as is shown in Figure 6(e). Grid connected current increases, however, under the grid side converter control system, it is limited to the normal range, as is shown in Figure 6(f). At the same time, the grid side converter will issue 0.4MVAR reactive power to help recovery the grid voltage under grid fault, as is shown in Figure $6(\mathrm{~g})$. When the grid occurs light drop fault, the generator speed, DC capacitor voltage and grid side current are all in the safe range, and PMSG achieves the low voltage ride through.

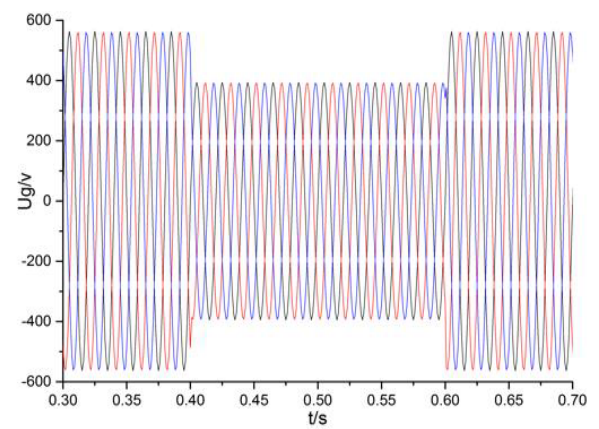

(a) Grid voltage

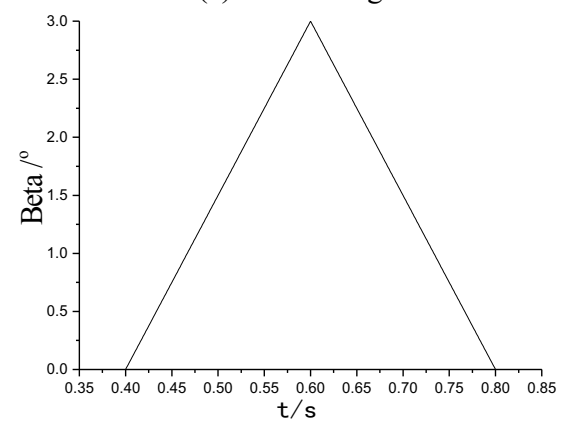

(b) Wind turbine pitch angle

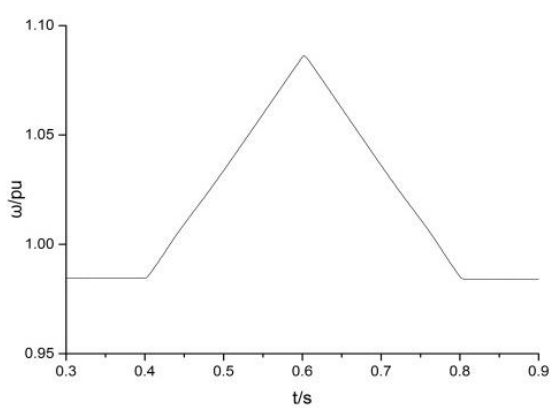

(c) Generator speed

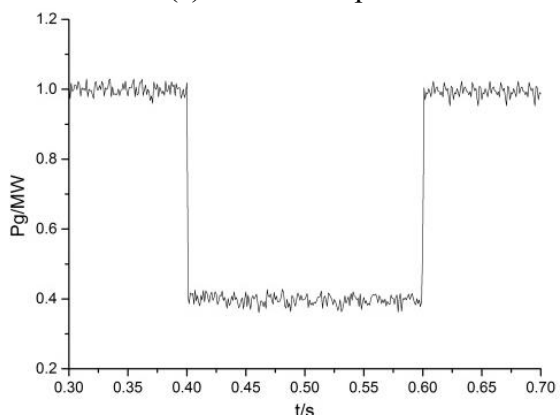

(d) Output active power of grid side converter

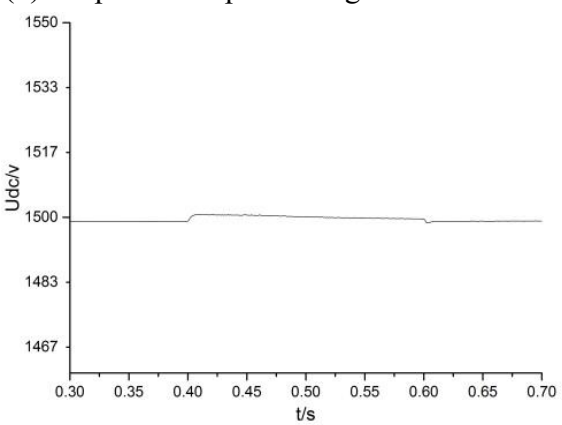

(e) DC side capacitor voltage

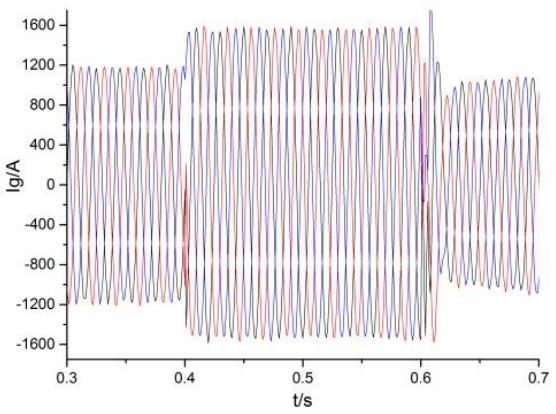

(f) Grid current

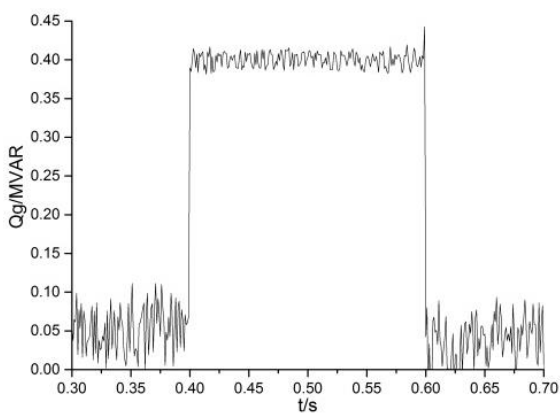

(g) Output reactive power of grid side converter Figure 6. Response waveforms of the grid voltage light drop.

Case 2: The deep drop of grid voltage simulation At $0.4 \mathrm{~s}$, the grid voltage occurs the three-phase symmetrical drop fault, the drop depth is $60 \%$, the 
duration time is $200 \mathrm{~ms}$, and at $0.6 \mathrm{~s}$ grid voltage recovers, as is shown in Figure 7(a). After the grid fault occurs, pitch angle control system begins to work, the pitch angle increases to decrease the wind energy captured by wind turbine, and the rotating speed of the generator increases as is shown in Figure 7(b) and Figure 7(c). By Figure 7(d), the capacity of the grid side converter to transfer power to the grid is reduced to $0.1 \mathrm{MW}$. The DC capacitor terminal voltage will have a transient overshoot, but under the machine side converter control system, the terminal voltage slowly drops until the normal value, as is shown in Figure 7(e). Grid connected current increases, however, under the grid side converter control system, it is limited to the normal range, as is shown in Figure 7(f). At the same time, the grid side converter will issue 0.63MVAR reactive power to help recovery the grid voltage under grid fault, as is shown in Figure $7(\mathrm{~g})$. When the grid occurs light drop fault, the generator speed, DC capacitor voltage and grid side current are all in the safe range, and PMSG achieves the low voltage ride through.

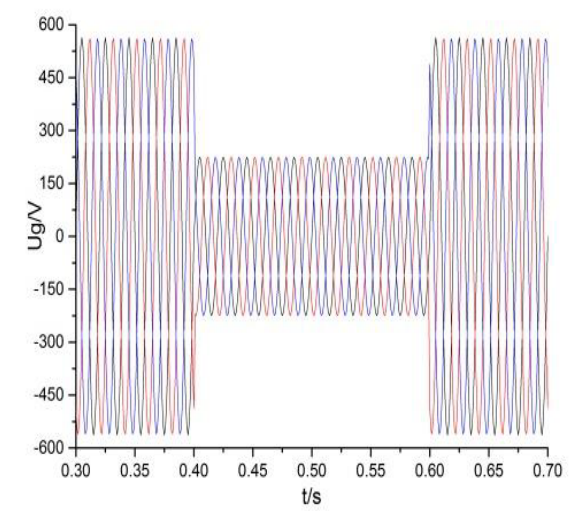

(a) Grid voltage

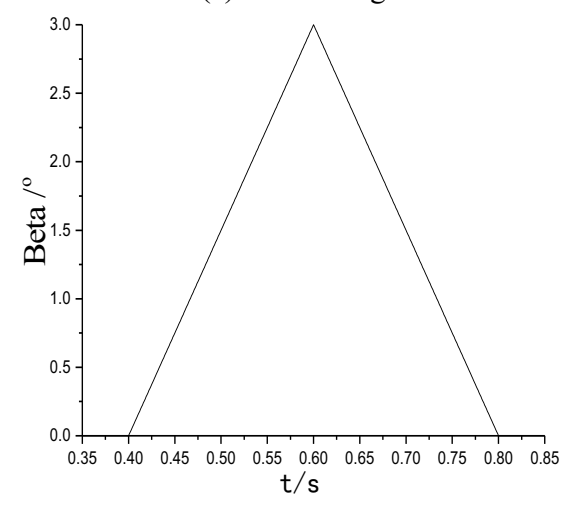

(b) Wind turbine pitch angle

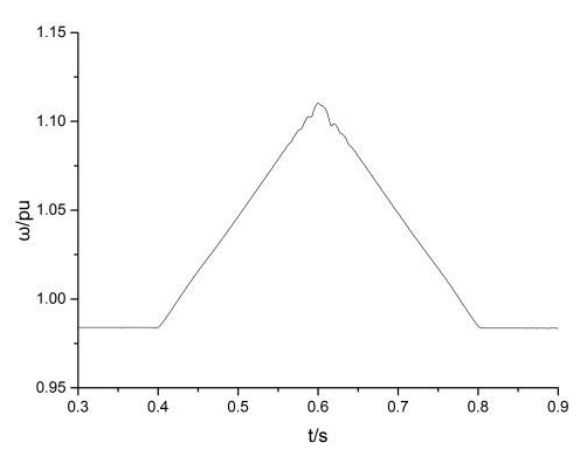

(c) Generator speed

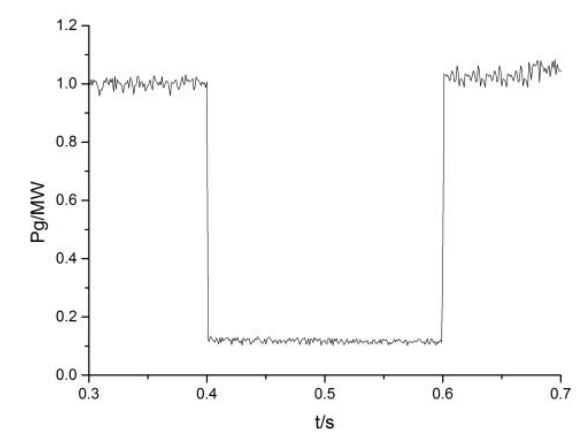

(d) Output active power of grid side converter

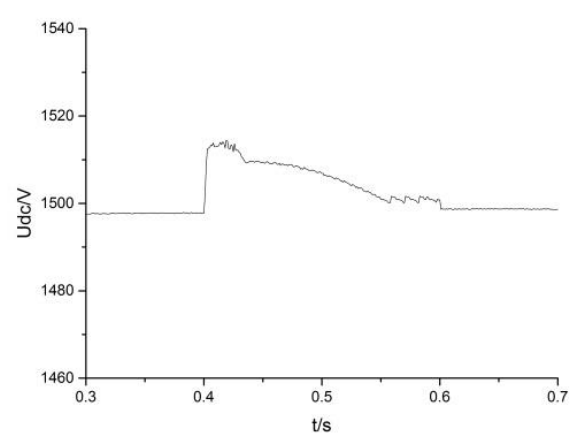

(e) DC side capacitor voltage

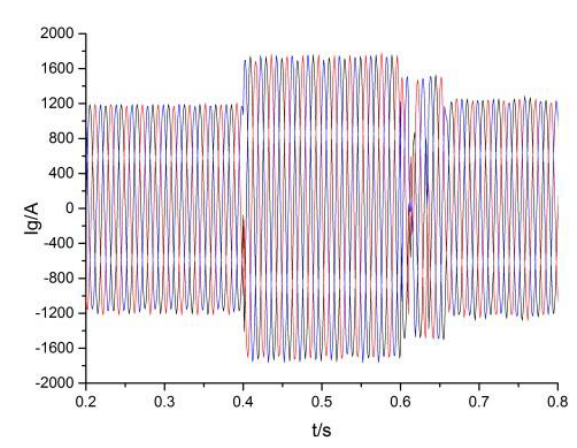

(f) Grid current

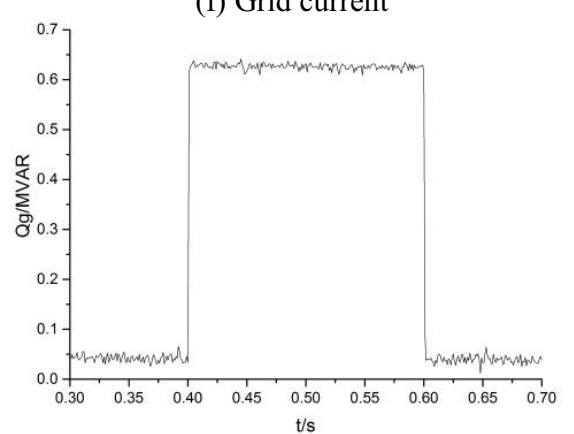

(g) Output reactive power of grid side converter Figure 7. Response waveforms of the grid voltage deep drop.

\section{Conclusion}

In this paper, a model of direct drive permanent magnet wind turbine under grid voltage drops is analyzed. Aiming at the energy imbalance between machine side convert and grid side convert, a coordinated control strategy including pitch angle control and inverter control is proposed and can avoid excessive generator over speed 
and the DC capacitor over voltage. Based on Matlab/Simulink, light drop and deep drop of grid voltage are simulated respectively. The simulation results show that the speed of generator and the DC capacitor voltage are limited to the safe range under grid voltage drops, and the permanent magnet direct drive wind turbine realizes low voltage ride through successfully.

\section{Acknowledgement}

This work was supported by Guangxi Power Grid limited liability company Scientific Project (GXKJ00000006).

\section{References}

1. XU, China's wind power installed capacity statistics of 2014, (2015)

2. W. P. Wang, A new LVRT method applied on the integration of distributed wind power generation: Electricity Distribution (CICED), 2012 China International Conference on, Shanghai, (2012)

3. Y. Liao, J. B. He, J. Yao, et al., Power Smoothing Control Strategy of direct-driven Permanent Magnet Synchronous Generator for Wind Turbine with Pitch Angle Control and Torque Dynamic Control, Proceedings of the CSEE, 18 (2009)

4. W. L. Wang, Grid-Connected Operation Control for Energy Storage based Direct-drive Permanent Magnet Wind Power system, Beijing Jiaotong University, (2010)

5. X. Zhang, L. Y. Zhang, S. Y. Yang, et al., Low Voltage Ride-through Technologiesin Wind Turbine Generation, Proceedings of the CSU-EPSA, 02 (2008)

6. Z. Chen, J. He, D. Wang, et al., A simplified wind farm simulation method for LVRT capability assessment: Power System Technology (POWERCON), 2014 International Conference on, Chengdu, (2014)

7. T. H. Nguyen, D. Lee, Advanced Fault Ride-Through Technique for PMSG Wind Turbine Systems Using Line-Side Converter as STATCOM, Industrial Electronics, IEEE Transactions on, 60(7):2842-2850, (2012)
8. J. Yao, X. M. Chen, X. F. Xia, et al., A Low Voltage Ride-through Control Strategy for Direct-driven Permanent Magnet wind Power Generation System with Flywheel Energy Storage Unit, Automation of Electric Power Systems, 13 (2012)

9. S. Y. Hou, Y. Fang, J. X. Zeng, et al., Application of supercapacitors to improve wind power system's low voltage ride through capability, Electric Machines and Control, 05 (2010)

10. Low Voltage Ride-Through Technique for PMSG Wind Turbine Systems Using Interval Type-2 Fuzzy Logic Control

11. S. Alepuz, A. Calle, Busquets-Monge S, et al., Use of Stored Energy in PMSG Rotor Inertia for Low-Voltage Ride-Through in Back-to-Back NPC Converter-Based Wind Power Systems, IEEE Transactions on Industrial Electronics, 60(5):1787-1796, (2013)

12. J. Yao, Y. Liao, K. Zhuang, A Low Voltage Ride-through Control Strategy of Permanent Magnet Direct-driven Wind Turbine Under Grid Faults, Automation of Electric Power Systems, (12):91-96, (2009)

13. S. Dong, Y. Wang, H. Li, Coordinated control for active and reactive power of PMSG-based wind turbine to enhance the LVRT capability: Electrical Machines and Systems (ICEMS), 2012 15th International Conference on, Sapporo, (2012)

14. H. Chen, X. B. Hu, G. G. Yan, et al., A Coordinated Control Strategy for Low Voltage Ride-Though of Direct-Drive Permanent Magnet Wind Power Generating Units, Power System Technology, (05):1464-1470, (2013)

15. Z. Y. Liu, C. R. Liu, G. Y. Li, Coordinated Power Control Method for Improving Low Voltage Ride Through Capability of Wind Turbines with Permanent Magnet Synchronous Generators, Automation of Electric Power Systems, (03):23-29, (2015)

16. X. Yang, X. Gong, W. Qiao, Mechanical sensorless maximum power tracking control for direct-drive PMSG wind turbines: Energy Conversion Congress and Exposition (ECCE), 2010 IEEE, Atlanta, GA, (2010) 